\title{
On the foreign legal supervision of the Variable Interest Entity
}

\author{
Yusheng Yang \\ ZheJiang University \\ GuangHua Law School \\ Hangzhou, China \\ 11701044@zju.edu.cn
}

\author{
keer Zhu \\ ZheJiang University \\ Economics College \\ Hangzhou, China \\ 11701026@zju.edu.cn
}

\begin{abstract}
The Variable Interest Entity, also known as VIE, usually refers to the separation of a listed company registered overseas and its entity operating in China. The listed company is an overseas company, and the overseas company controls the domestic business entity through agreement. Variable Interest Entities is a way for Chinese companies to achieve overseas listing. In the case that domestic financing channels are not smooth, domestic capital market development is imperfect, and financial support is urgently needed, this kind of listing, chosen as the last resort, has its own rationality in existence and development. Under the premise that companies listed on the VIE structure have already existed in abundance, how to strengthen supervision is an important issue that needs to be solved urgently. This paper intends to start from the Sina listing case to analyze the concept and cause of overseas listing and agreement control mode; secondly, analyze the current status of the regulatory system; then, focus on the harm caused by the lack of supervision; finally, explore different ways to solve the problems in VIE supervision, looking forward to a little inspiration for the theory and practice of the VIE structure.
\end{abstract}

Keywords-Variable Interest Entity; legal dilemma; information disclosure; regulatory system

\section{The BAsic ConcePt of VIE Structure}

\section{A. Basic Definition}

The full name of VIE is Variable Interest Entity, which means that the listed entity registered overseas is separated from the domestic business operational entity. The overseas listed entity controls the domestic business entity through agreement. The business entity is the VIE of a listed entity. Created in the US accounting standards, it is a term about the description of the invested entity, but for its accurate definition, the academic community still has no consensus on this point. As for the definition of the VIE structure itself, the common practice in the world is to use the definition of American financial accounting standards board as its general standard.

\section{B. Research on Sina's Listing Case}

In 1999, sina.com successfully raised funds and was about to receive capital injection from foreign investors. However, in 1993, the Ministry of Industry and Information Technology of China and the State Administration of Press and Publication jointly issued the "regulations on value-added Internet Services" for Internet enterprises, which stipulated that foreign companies were prohibited from operating in the related fields of online information services. The degree made Sina's financing plan deadlocked, and then Sina seized the relevant provisions of "Telecommunication Act" that prohibits foreign involvement in telecommunications operations and telecommunications value-added services, and foreign companies cannot provide network information services, but can provide technical services. Sitong Lifang, the original operating entity of Sina Company, split the related services such as Internet information and telecommunications value-added services. Then, for the purpose of overseas listing, a series of control structures were established, overseas offshore companies were established in tax havens, and a large number of control agreements were signed, and organizational restructuring was carried out.

Sina has made a series of reforms in order to go public. At the beginning, Sina was first led by Wang Zhidong, the founder of Sina.com, and the founder of Sitong Lifang Company. He set up a wholly-owned company, Beijing Sina Information Service Co., Ltd., which is owned by a natural person, and applied to the Internet authorities of China for the ICP (Internet Content Provider) license. At the same time, Beijing Sitong Lifang Information Technology Co., Ltd., which was the predecessor of Sina.com, became a purely joint venture company. It was controlled by Hong Kong Cube Investment Co., Ltd. and provided server maintenance, software and hardware support and management consulting to Beijing Sina. Comprehensive technical services in several aspects. Then Beijing Sina Interactive Advertising Co., Ltd. was set up, which was mainly used as the agent of Beijing Sina's advertising business. It exclusively rented the advertising space of all websites of Beijing Sina. The actual controller of this company was also Cayman Sina. Finally, Beijing Sitong Lifang provided technical and management services for the advertising company.

By then, Cayman Sina had not acquired all the assets of Sina.com in China in the form of equity control, but the vast majority of its profits had passed the above various agreements in its corporate structure. The perfect transfer, in the end, finally reached the hands of shareholders and investors of listed companies. It is also because of these agreements and the special structure that they have formed the actual control of domestic enterprises without the control of equity. This structure was established and widely adopted by international investors in companies listed overseas in China. First, an 
international investor and an investor establish a company A registered overseas, and then establish a technical service company $\mathrm{B}$ under its actual control, and control the entire domestic company $\mathrm{C}$ of the telecommunications license through agreement, and the profit is transferred to B through the agreement. This is the basic model of the VIE structure, and the industry has also turned it into a "Sina structure".

\section{The Current Status of the Regulatory System}

It can be said that China's law on the existence of the VIE model enterprises is a blank. This type of enterprise and model are not explicitly defined throughout the legal system. At present, the identification of this model basically relies on the "Contract Law" to identify its control agreement as a civil and commercial contract between equal subjects, in accordance with the principle of autonomy of will and the relevant provisions of the general contract. On the other hand, since there is no relevant provision, according to a basic jurisprudence that "the law is not expressly prohibited, that is, freedom”, it must be able to be affirmed, so its validity should be confirmed and effective. But even so, it is obviously unreasonable that an effective civil act which is not prohibited by law under the expression of free truth can't be legally recognized or even ignored, and thus cannot be adequately protected.

At present, some regulators believe that such an agreement for the purpose of evading regulations should not be considered valid and it is a contract invalidation that "cover illegal purposes in a legal form”. In fact, this argument is not based on sufficient evidence. Although it is negligible to circumvent legal supervision, it is not an "illegal purpose" to avoid legal supervision by means not prohibited by law, and the law itself does not prohibit the use of legal gaps or omissions for profit. What's more, this business model does not damage the unification of the rule of law and the common benefits of society, and it even brings about the vigorous development of related industries and the spurt of technology in China. For this pioneering innovation, it should be incorporated into the legal system of China, not to suppress or ban this kind of approach, but to hope that it can develop healthily in a controllable state, so that it can be protected and the interests of the parties involved can be guaranteed.

At present, the supervision in China is often based on the role of the regulator, trying to ensure that the entire industry system of the VIE is not separated from the scope of China's foreign capital merger and acquisition and foreign exchange management, and does not protect the interests of domestic and foreign investors of China's VIE model enterprises. The lack of protection not only affects the interests of investors, but also adversely affects the process of the listing of the VIE in the overseas capital market. Overseas investors' concerns about this potential legal risk often slow down the listing of the VIE, which in turn impedes the development of the company. The most typical example of this is the listing of Tudou. When Tudou established a complete VIE structure after years of preparation, the wife of Wang Wei, the founder of Tudou and the actual controller of a wholly-owned enterprise in China, filed for divorce and demanded a 38 percent stake in Tudou. The Nasdaq exchange believes that their divorce lawsuit may cause listed companies to lose control of domestic companies, so they suspended the listing process until the fall of 2011, with Wang Wei paying $\$ 7$ million as a precondition for reconciliation. [1]At this time, Tudou online market shelved nearly a year, and its biggest competitor Youku, listing 8 months earlier, used the financing to expand rapidly. Since then, Tudou has gradually declined and was acquired by Youku in 2012.[2]

However, there are many regulatory authorities in China, and the executive departments of most regulatory rules are independent and there is no coordination and coordination. Therefore, there is no complete combination of their responsibilities for many things, leading to overlapping or conflict of regulatory powers. In this way, in practice, there are often diametrically opposite attitudes and rules for different regulators, perhaps even for the same matter, which makes VIE enterprise feel at a loss. At the same time, there may be a regulatory vacuum, which will not only damage the interests of the VIE enterprises, but also bring a relatively negative impact on the regulation itself. Therefore, it is necessary to coordinate the supervision of the VIE enterprises, formulate a consistent regulatory policy, and promote the hierarchy of such rules, so that the VIE enterprises can develop much more healthily. At the same time, Chinese regulators usually only regulate the existing phenomena passively, and do not give advance evaluation of the possible risks. This leaves the entire regulatory rules fall behind practice, which is one of the reasons for the commercial failure of Tudou.

However, the idea that China has always dominated the structure of VIE enterprises is not in line with the actual needs of China's vast number of start-ups at this stage. This kind of obstacle can't completely reduce the determination of VIE enterprises to seek overseas listing, but will make them cope. The process of regulating barriers consumes a lot of resources and energy, which often causes it to be frustrated in business, and is more detrimental to international competitiveness, so that it cannot create social wealth better. Moreover, this kind of review is impossible to review every legal agreement and contract of a legally established enterprise. In the case of such negative supervision, the enterprise will not actively report the VIE related control agreement. Therefore, in fact, the regulatory measures are no different from the Maginot line of defense. Only by guiding the interests of the parties in the interests of VIE can the VIE enterprises actively disclose control agreements, seek protection, and achieve effective supervision of the risks.

The main reasons are as follows: First, the valuation is low. After a wave of short selling, the prosperity of Chinese concept stocks in the US market has disappeared since long time ago. Instead, they are worried about the intrinsic disadvantages such as insufficient information and unclear shareholding structure. This worry has naturally led to lower expectations among US investors, and a slightly lower valuation for the stocks in the VIE. Second, there are too many disputes. China's VIE concept stocks are not well connected to the United States between finance and statements, and the outsourcing of audit work is often flawed in many details. The US law firm often seeks the shackles of China's VIE listed companies for the purpose of profit, and as a basis for this; the shareholders filed 
class-action lawsuits and made a fortune. Although not always able to win, for China's VIE enterprises it is also annoying, resulting in poor operational management and then efficiency is affected. [3]Furthermore, there are great cultural differences between China and foreign countries. For Chinese enterprises' own business model and profit model, the US investors themselves have a weak sense of identity, and there is a little unrealistic judgment on China's national conditions. Similarly, in terms of values, it is also hard to get recognition from foreign investors, such as those in industries like traditional Chinese medicine and health care, which have been shunned by American investors. Third, the market environment has deteriorated. In the first few years of the United States, economic growth has become slower, but China is in a period of rapid growth. US investors are optimistic about China's economic development. Naturally, the market value of Chinese VIE enterprises is also high, but as the global economic slowdown, China is no longer able to maintain the rapid growth, so it is no longer tempting for US investors. In contrast, the US domestic capital market is also facing the edge of recession, which is no longer the trend of soaring, which also promotes the return of China's VIE listed companies. Finally, the cash-out of major shareholders. At the same time that China's VIE enterprises are privatized and delisted, for the relevant shareholders, they will timely cash out according to the situation to ensure their wealth increases. At this time, if the return to the local market is listed, in the case of share reorganization, the opportunity is more likely to make the stock price high, bringing a blow to the wealth of shareholders, just like the Storm Video did. In addition, in many cases, the delisting of the stocks in VIE is also for the company to make a better strategic adjustment and optimization of the ownership structure. VIE companies usually go public in the US when they need to expand their financing. However, when the rapid expansion period came to an end, the demand for huge funds was not imminent, and the priority becomes to consolidate profits for the company, carry out strategic transformation and resource integration, and find the next strategic growth point. At this point, the complex VIE structure may no longer be applicable, but it will drag down the company's execution efficiency and bring unnecessary legal risks.

\section{Multiple Solutions to the Supervision OF the VIE}

\section{A. Improvement of the Registration System and the General Disclosure Mechanism of Listed Companies}

China is planning to revise the Securities Law, and its forerunner is to advance the reform of the registration system for stock issuance. As the regulator of the capital market, the government will shift from the paternalistic responsibility to the supervision of "night watchmen", and from the pre-supervisor approval to the post-supervision.

As one of the basic systems of mature capital markets in the world, the registration system plays a positive role in promoting the listed financing of enterprises, and correspondingly it is a perfect information disclosure system. [4]For VIE enterprises, it can reduce the legal cost of many domestic listings. As long as the information disclosed is in line with the legal provisions, the VIE enterprises that are not in the prohibition or restriction list can directly raise funds in the A-share listing in China. In the United States, for example, the role of SEC is not to review the performance and institutions of the listed company. It is a typical post-supervision system to ensure that the information disclosure is legal. However, the information disclosure in China has become a form after going south, and the decision of investors and regulators does not take the disclosure as the most important basis. A comprehensive, timely and accurate information disclosure system should be established to severely punish those who make false statements and maliciously cheat, so that both the market and the judicial authorities can take a two-pronged approach and pursue their responsibility for breach of information disclosure obligations.

In this regard, the role of market supervision is actually the main aspect. If the participants can make good use of their judgment on the behavior of listed companies, they can better supervise the activities of these listed companies, especially those with the VIE structure. Just as VIE companies are short-selling by US investors, they are suspected of failing to fulfill their full information disclosure obligations, causing market suspicion and short-selling shorts. If the information disclosure can be guaranteed, then the registration system can't only ensure that the VIE enterprises are successfully listed and financed in China, but also can always monitor whether they make any false statements at any time during the listing financing and if there are any violations of China's regulations on prohibition or restriction, and then investigate their responsibilities and imposes severe penalties.[5]

\section{B. Listing of Strategic Emerging Board and Special Equity Structure Enterprises}

According to the information previously disclosed by the State Council and the Shanghai Stock Exchange, China's strategic emerging board, which is in full swing, is approaching One of its goals is to open up a battlefield for the return of China's overseas VIE concept stocks. In the State Council meeting, Premier Li Keqiang clearly stated that "the relevant legal rules should be improved to promote the listing of enterprises with special shareholding structure in China." Enterprises with VIE structure are included within the special equity structure enterprises.

The establishment of this new emerging sector has fully considered the fact that most of the previous sectors in China were established only with traditional industries as templates, and they did not distinguish well between different sectors. Therefore, the cluster effect of the emerging science and technology industries and the new equity structure cannot be fully played. Most of the VIE enterprises are also emerging technology industries, so the launch of the strategic emerging board can well undertake the return of such enterprises. Meanwhile, it also attracts the VIE enterprises which have not considered listing before, such as Jingdong Finance, which makes it clear that the first choice is to go public in the strategic emerging board. In addition, as a special shareholding structure enterprise, the VIE enterprise is closer to the governance structure of the equity-based crowd funding compared with the traditional enterprises in main board. Therefore, if it can be in the strategic emerging board, it will also facilitate the coordinated development and form a synergy. 
The strategic emerging board is different from the system design of the main board, which is more conducive to the listing financing of VIE enterprises, and also facilitates the successful exit of international strategic investors. It also plays a positive role in attracting early strategic investment. In addition, if the Foreign Investment Law (Draft) can be implemented smoothly, the legal risks faced by the VIE enterprises can be minimized, which is of great benefit to the internationalization of China's VIE enterprises.[6]

\section{CONCLUSION}

This paper explores the definition and development process of VIE enterprises, revealing that it belongs to a special shareholding structure generated in practice under special regulatory conditions, and its purpose is to circumvent the current regulatory system. According to the practice in recent years, although it has a positive effect on the introduction of foreign investment by private enterprises in China, the legal risks it faces are not to be underestimated. After discussing the dilemma and possible solutions,[7] the author believes that the innovative products of this shareholding structure should not be dealt with in a negative attitude, and should be systematically regulated and supervised to reduce its legal risk. In particular, it should be given its due legal status in the newly enacted Foreign Investment Law. China's regulators should actively seek a variety of ways to make the VIE return to the domestic capital market, and supervise the development of the VIE enterprise in a healthy and mature way in terms of supervision and policies.

\section{REFERENCES}

[1] Benjamin R Silliman, "Variable interest entities: revised guidance to improve financial reporting," Commercial Lending Review, Vol.25, pp. 31-37, 2010.

[2] D. Lange, and J. M. Fornaro, “Consolidation of variable interest entities for private companies,” CPA Journal, Vol.87, pp. 46-50, 2017.

[3] M. Pagano; A. A. Röell, and J. Zechner, "The geography of equity listing: why do companies list abroad?” Journal of Finance, Vol.57, pp. 2651-2694, 2002.

[4] Q. Tang, “Legal Regulation on Agreement-control,” Shenzhen. China: Securities Market Herald, pp. 17-22, 2012.

[5] W. T. Chen, The Regulatory Issues Research in China of Contractual Control Mode, Shanghai. China: East China University of Political Science and Law, 2016.

[6] Y. T. Wu, On the Legal and Regulatory Compliance of VIE Corporate, Beijing. China: China University of Political Science and Law, 2015.

[7] Z. J. Chen, "The legal validity and perfection of the regulation of the VIE agreement,” Jilin. China: Public Administration \& Law, pp.119-125, 2013. 